Página inicial: 413 - Página Final: 426

Tipo de artículo: Investigación

\title{
Resistencias y territorialidades Indígenas en el sur del Tolima ${ }^{i}$
}

\author{
Indigenous Resistance and Territoriality in the Southern Region of the State of Tolima
}

Recibido: abril de $2017 \quad$ Revisado: mayo de $2017 \quad$ Aceptado:junio de 2017

Por: Francisco Antonio Arias Murillo ${ }^{1}$ \& Diego Mauricio Duque Rodríguez ${ }^{2}$

1 Doctor en Ciencias Sociales, Niñez y Juventud; Postdoctor en Narrativa y Ciencia; profesor investigador de planta de la Universidad del Tolima, Facultad de Ciencias Humanas y Artes; miembro de los grupos de investigación: "Educarte" e "Indaguemos-Salud". Coordinador del Grupo de Estudio "Diatribas Contemporáneas".

Director de la Maestría en Territorio, Conflicto y Cultura. Contacto: faariasm@ut.edu.co efearmu@gmail.com

2 Politólogo. Tesista laureado del programa de Ciencia Política, Facultad de Ciencias Humanas y Artes, Universidad del Tolima. Miembro fundador del Grupo de Estudio y Semillero de Investigación "Diatribas Contemporáneas" de la Universidad del Tolima. Contacto: duque5304@gmail.com

\section{Resumen}

Arqueológicamente se diagnostica las luchas indígenas por el territorio en el sur del Tolima; genealógicamente, se analizan formas de resistencia emergentes, especialmente, del «Gran Resguardo de Ortega y Chaparral», como prácticas y formas discursivas fundadas en reivindicaciones de Manuel Quintín Lame, que propiciaron la conformación de un movimiento social. Como metodologías, la arqueología describe y muestra lo efectivamente dicho por Quintín Lame y sus difusores; la genealogía permite análisis críticos, alternativos -no autorizados, ilegítimos- de múltiples fuerzas que atraviesan y tensionan los discursos, para visibilizar aquello que tendenciosamente se procura que no sea visto, por los implicados en el hecho.

Palabras clave. prácticas y formas discursivas; movimiento social de resistencia; territorialidades indígenas; fuerzas que tensionan discursos.

\begin{abstract}
Archaeologically, diagnosed indigenous struggles for territory in the south of Tolima are diagnosed; genealogically, emerging forms of resistance, especially, those of the "Great Ortega and Chaparral Indigenous Reservation," are analyzed as practices and discursive forms based on the claims of Manuel Quintin Lame, which encouraged the formation of a movement social. As methodologies, archaeology describes and shows what was actually said by Quintin Lame and their disseminators. Genealogy allows unauthorized, illegitimate critical, alternative, analyses- of multiple forces, which cross and strain speeches in order to make visible that which is tendentiously sought not to be seen, by those involved in the fact.
\end{abstract}

Key words: Discursive Practices and Forms; Social Movement of Resistance; Indigenous Territoriality; Forces Straining Discourse. 


\section{Introducción}

El texto muestra un proceso de investigación sobre las relaciones en torno de la territorialidad y el conflicto en el contexto colombiano. El caso en cuestión, -resistencias y territorialidades indígenas en el Sur del Tolima-, traza una ruta de análisis arqueológico y genealógico, en perspectiva de Foucault (1969, 1996), con el fin de visibilizar lo dicho por Manuel Quintín Lame y sus difusores, y caracterizar algunas formas del movimiento de resistencia: en particular, las relacionadas con el «Gran Resguardo de Ortega y Chaparral», comunidad ancestral, vigente aún y presente en la etapa de la colonización española, cuyas reuniones, organizaciones y actuaciones desarrolladas a través de cabildos, se basaron, contemporáneamente, en algunas prácticas discursivas fundadas en ejercicios reivindicatorios de Manuel Quintín Lame, líder indígena de ascendencia Paéz quien reunió y organizó a indígenas de ascendencia Coyaima y Natagaima en la zona Sur del Tolima. A lo largo de su vida, este líder luchó por concentrar 26 parcialidades en Ortega y Chaparral, principalmente, desde la década de 1930 hasta su muerte en 1967, para efectos políticos de defensa territorial comunitaria, ligados, a su vez, con otros resguardos indígenas en el Huila, Cauca y Tolima. Algunas de sus reivindicaciones locales sirvieron de base, junto a otras, para la consolidación de procesos de organización posteriores como la formación del CRIT (Concejo Regional Indígena del Tolima), CRIC (Consejo Regional Indígena del Cauca) (Tello, 1986, pp. 151-152) y la ONIC (Organización Nacional Indígena de Colombia), así como el posterior reconocimiento, a nivel nacional, de derechos decretados luego de la Asamblea Nacional Constituyente de 1991; sucesos éstos que permiten mostrar, posiblemente, cómo un acontecimiento, una singularidad, puede cambiar y potenciar - sin pretender determinar ni predecir- la historia de las comunidades indígenas en la actualidad, permitiendo que otros discursos puedan emerger para defender su concepción particular de vivir el territorio.

Con base en esta perspectiva, contextualizar algunos enunciados discursivos de resistencia lamista permite reconocer y poner en circulación distintas fuerzas de resistencia social, política, económica y cultural en cuya emergencia y análisis triangular, esto es, allí donde surgen, se transforman e influyen en el campo de lo político, se pueden develar sus continuidades y discontinuidades con los mecanismos de poder de los cuales son sujetos: por un lado, en su uso estratégico del derecho positivo y de gentes, y por el otro, de principios doctrinarios de la ética y moral católicas que utilizan, junto a sus prácticas autóctonas, como dispositivos constitutivos de su discurso liberador. Al analizar esta formación discursiva que se va gestando por medio de la difusión, reconocimiento y dispersión de los postulados de este movimiento social de resistencia, hacia una perspectiva política más general, es posible mostrar su relevancia dentro de la defensa, indígena, del territorio y a través de su puesta en escena, evidenciar una fuerte interdisciplinariedad que, de ser usada, -eventualmente-, en los constructos de una posible teoría política, podría dilucidar una formación discursiva, no solo de pretensión general sino hasta universal, que interactúe con las particularidades de las cuales el discurso mismo surge. (Deleuze, 2005, pp. 49-105).

Para tal propósito, se describen las prácticas discursivas. Ellas se refieren a las formas "que tiene el saber de ponerse en práctica en una sociedad" (Foucault, 2010, p. 22), las que, en cuanto que "prácticas discontinuas que se cruzan, a veces se yuxtaponen, pero que también se ignoran o se excluyen" ( $p$. 53), resulta factible visibilizarlas a través de la estrategia arqueológica, toda vez que su objetivo procure el "análisis de las discursividades locales" (Foucault, 1996, p. 20). En razón de lo anterior, se procedió a la creación de un "archivo" (Foucault, 1970, p. 222), entendido como "el sistema general de la formación 
$y$ de la transformación de los enunciados" (p. 221) La multiplicidad de enunciados expone su funcionamiento como registro de saberes singulares, atávicos, enmarañados, a veces, descalificados, en los decires de los integrantes del movimiento social indígena de resistencia: en la recolección de documentos legales ligados a sus reivindicaciones, textos escritos por Manuel Quintín Lame, así como fuentes orales recabadas en testimonios tomados en los Resguardos de Yaguará en Chaparral y Guatavita-Túa y Vuelta'el Río en Ortega, Tolima. De este modo se facilitó analizar sus prácticas discursivas en sus formas locales de emergencia.

En perspectiva foucaultiana los enunciados son considerados acontecimiento, es decir, tramas de múltiples fuerzas que permiten que emerja, en un momento dado, un suceso que zanja la historia para que aparezca la novedad; esto hace posible pasar a un segundo componente, genealógico, toda vez que sea empleado como "acoplamiento de un saber histórico de las luchas y la utilización de este saber en las tácticas actuales” (Foucault, 1996, p. 18). Recurriendo tanto a la arqueología como a la genealogía, se registraron enunciados procedentes de algunas crónicas, textos antiguos y raros referidos a la voluntad de verdad que permiten pensar la emergencia del resguardo como dispositivo de poder soberano (monárquico), tras la Conquista Española, para analizar, en su trayectoria, qué fuerzas de resistencia indígenas e indigenistas emergieron, junto con sus puntos de quiebre y sus múltiples resonancias en la actualidad. A este respecto, es clave el siguiente enunciado para guiar esta reflexión conjunta: "Lo nuevo no está en lo que se dice, sino en el acontecimiento de su retorno” (Foucault, 2010, p. 29).

\section{Resistencias y territorialidades}

Algunos postulados trabajados sobre la concepción de movimiento social de resistencia podrían ser, en primera instancia, como dispositivo de lucha por los derechos individuales y colectivos, lo cual implica la lucha "contra un adversario por el control de un campo social' (Touraine, 1997, p. 262). Segundo, sus integrantes reconocen una identidad común entre sus participantes que busca ser movilizada (Touraine, 1997; Melucci, 2010; Tarrow, 1997). Tercero, un movimiento social de resistencia puede ser analizado como movimiento político en la medida en que busque "lograr cambios fundamentales estructurales (cambios sociales), [pero a su vez, un movimiento político es un movimiento social de resistencia en cuanto se sitúa] en las contradicciones sociales y en los conflictos" (Raschke, 1994, p. 130). Cuarto, si un movimiento social de resistencia implica un "conjunto cambiante de debates, tensiones y desgarramientos internos (...) entre la expresión de la base y los proyectos políticos de los dirigentes" (Touraine, 1997, p. 104) lo más probable es que su principal tendencia sea el cambio y la conflictividad constantes. Quinto, su poder sociopolítico depende de la capacidad de concentrar todas las fuerzas que se reúnen en un movimiento social con el fin de hacerlas confluir continuamente alrededor de su propia historia para transformar la sociedad a la que pertenecen (Foucault, 1996, p. 49) Sexto, para los análisis locales de movimientos sociales de resistencia, es necesario distinguir y estudiar más que el "movimiento de la sociedad", el rastro de lo que puede ser "un movimiento social" (Raschke, 1994, p. 127) Séptimo, dentro de este análisis concreto, los movimientos sociales de resistencia:

Suponen una situación de confluencia de planos de realidad donde se manifiesta la relación de la memoria (reconstrucción del pasado) con la praxis (apropiación del presente), con la utopía (apropiación del futuro) y con la representación que el sujeto tiene de ese proceso gracias a su conciencia (la dimensión meta del conocimiento). (Guerra, 1997, p. 113) 
Dentro de este orden de ideas, -cuyo objetivo articula la mostración de las prácticas discursivas lamistas-, se propone una aproximación al concepto de movimiento social de resistencia como una confluencia continua de múltiples disputas locales que responden a problemáticas más generales vividas y sentidas por un grupo de personas, cuyas acciones colectivas parecen estar reconocidas y justificadas por la búsqueda consciente de orientar sus objetivos hacia la transformación sociopolítica de sus realidades más cercanas, utilizando para ello "formas organizativas y de acción variables" (Raschke, 1994, p. 124). Se sigue esta vía conceptual para describir, a modo de acontecimiento, cuáles y cómo han sido las prácticas discursivas -visibles en los enunciados discursivos de Manuel Quintín Lame- y, a partir de ello, evidenciar en sus formas la emergencia de fuerzas de resistencia política, económica, cultural y social.

Aproximarse de este modo a un movimiento social de resistencia, -cuyos enunciados refieren una realidad principal pero no exclusivamente indígena-, implica reconocer, a su vez, que las resistencias se interrelacionan con las territorialidades. Habida cuenta de la búsqueda de transformación sociopolítica que los movimientos sociales de resistencia pretenden lograr en las realidades más cercanas de su población, en este caso, los indígenas, ¿Cómo entienden ellos su relación con el territorio a la luz de estos postulados? Uno de los integrantes del resguardo Vuelta'el Río, en Ortega, Tolima, comienza por exponer su perspectiva sobre el Gran Resguardo de Ortega y Chaparral:

(...) recordemos que los indígenas ancestralmente han vivido y hemos vivido en estos territorios, pero por distintos fenómenos, como jue (sic) la llegada de los españoles, y después las guerras entre liberales y conservadores y las guerras civiles que ha tenido Colombia..., estas tierras han llegado a mano de particulares, entonces, digamos, hay una dualidad que es, las comunidades tienen, reconocen y reclaman un territorio ancestral; la Corona española, —entre 1600 y 1700 - promulga los Resguardos indígenas, —en este caso los dos grandes Resguardos, el que hablamos de el Gran Resguardo de Ortega y Chaparral y el de Natagaima, ¿sí?-. Pero también se superpone las escrituras ya públicas a nivel privado. Entonces, esa es, digamos, la gran discusión que hay y el gran conflicto que se ha llevao' (sic) por las tierras, porque las comunidades seguirán reclamando sus territorios ancestrales... (Entrevista 1, 05:03-06:08)

Este relato permite entrever varios aspectos a destacar. Desde la perspectiva más general, el territorio constituye una relación íntima entre el indígena y la tierra que produce, pues para él representa "la madre, la fuente de vida, un concepto donde el hombre es un ser de naturaleza" (Rojas, 2000, p. 71). La conflictividad emerge toda vez que la territorialidad, como multiplicidad de relaciones ancestrales con el territorio, surja como punto de partida para reconocer la identidad del indígena frente a la que buscan disociar los particulares que, tras la Independencia, buscaron dividir sus territorios para comprar y vender sus tierras, desconociendo sus derechos comunales. En este sentido, la territorialidad indígena, implica, una lucha constante por ser reconocidos como ciudadanos en el orden civil y político, pero siempre y cuando se respeten sus diferencias en los territorios que conforman su historicidad como indígenas. De este modo, sus organizaciones y acciones variables, en cuyo objetivo se encuentra el territorio como sociedad particular, se desplazan en los límites del sistema político colombiano, - pero no se oponen a éste-. De ahí que se haya

(...) movido en el campo de la resistencia, es decir, no han cuestionado el actual sistema, no han pensado en un pachacutec (sic), ni en una ruptura radical de las relaciones que los atan a 
la sociedad colombiana, al contrario, se piensan como colombianos y piden reconocimiento de derechos como partes integrantes de Colombia. (Vasco, 2008, p. 382)

Debe señalarse que aunque no se ha cuestionado el sistema político nacional, sí se han cuestionado las formas en que se ha desconocido, histórica y violentamente, la propiedad ancestral de los indígenas en el país, frente a los cuales, la lucha por el Gran Resguardo de Ortega y Chaparral, constituye un ejemplo paradigmático. En ella se reconoce, principal, pero no exclusivamente, en la figura de Quintín Lame, -junto a Abel Tique, José Gonzalo Sánchez, Escolástico Ducuara, entre muchos otros-, un líder visible que proyectaba, en sus discursos, la participación de indígenas en el Congreso, a través de una plataforma regional de elección política de representantes desde el Tolima, el Cauca y el Huila (Cf, Theodosiadis, 2004, p. 66), pero también, una forma de autoridad que buscara defender los cabildos otorgados por la ley 89 de 1890, para defender los resguardos a nivel nacional:

El indígena colombiano debe tener su representación en el Senado de la República y en la Cámara Baja, en las Asambleas Departamentales y en los Concejos Municipales, por las razones siguientes:

a) Porque el legislador da órdenes contrarias y dicta leyes contra la propiedad comunal de los indígenas por su ignorancia;

b) El legislador ordena que repartamos nuestros terrenos de resguardos, pero no dice que el blanco, que tiene sus latifundios, también los reparta (...)

c) Como medio más apropiado para reivindicar nuestra raza proscrita y abandonada por la civilización colombiana. (Lame, 1939/1987, p. 29)

Se evidencia en este discurso la emergencia política de este movimiento social de resistencia, toda vez que sus reivindicaciones, dirigidas hacia el sistema político, fueron esgrimidas, posteriormente, en la Constitución de 1991 por representantes como Lorenzo Muelas (Ariza, 2009, p. 255). Resonancias de estas luchas las proporciona el actual estatuto ciudadano:

el derecho a autogobernarse bajo la forma de cabildo (o de otra autoridad propia de la comunidad) y, más generalmente, una serie de derechos particulares ligados al estatuto indígena: atención gratuita en los hospitales, educación bilingüe y bicultural, acceso gratuito a la universidad, exención del servicio militar y de los impuestos sobre la tierra, derecho a ser juzgado según sus usos y costumbres dentro del seno de la comunidad y, desde la Constitución de 1991, derecho a transferencias del presupuesto nacional, a una protección de su medio ambiente y a dos senadores indígenas elegidos por circunscripción electoral especial. (Gros, 2012, p. 64)

Si toda reflexión sobre un movimiento social de resistencia se inscribe dentro de una confluencia de múltiples planos de realidad donde las disputas locales responden a problemáticas más generales, ¿cuál es la problemática histórica, que presentan los postulados de Quintín Lame? Son dos modalidades enunciativas las que presenta, de manera histórica, el lamismo en el sur del Tolima, que poseen un cierto nivel de generalidad para las luchas indígenas en Colombia (Deleuze, 2005), al referirse a sus territorialidades: el de la denuncia de ocupación de territorios indígenas por los conquistadores españoles (aproximadamente desde el siglo XV en adelante) y el de la recuperación paulatina de los resguardos 
arrebatados desde ésta época (Cf, Rojas, 2000), debido a que "su derecho es anterior a toda legislación civil colombiana" (Castrillón, 1973, p. 218). Es el resguardo, como territorio ancestral de supervivencia de la historia indígena, una "forma a través de la cual se expresa con mayor nitidez todo el proceso de ocupación-recuperación” (Rojas, 2000, p. 71). La situación problemática del resguardo se puede evidenciar en el terraje, el cual se refiere a

(...) una relación de carácter feudal, servil, según la cual un indígena debía pagar en trabajo gratuito dentro de la hacienda el derecho a vivir y usufructuar una pequeña parcela, ubicada en las mismas tierras que les fueron arrebatadas a los resguardos indígenas por los terratenientes. (Vasco, 2008, p. 373)

En ella confluyen, desde la perspectiva indígena, no sólo una relación de dominación única, estructural, unidireccional, sino, antes bien, una red de "poderes hacendiles, políticos, eclesiásticos y militares" (Triana, 1993, p. 100) que busca naturalizar el despojo de tierras a los pobladores de resguardos para entregárselos a particulares, ya sean usurpadores o compradores, quienes se alían con las alcaldías, personerías y demás entidades locales, para desconocer las leyes especiales que defienden sus territorios.

Ciertamente, no somos los únicos en analizar las relaciones de poder en red en los movimientos sociales. Para un caso latinoamericano clásico, véase Lomnitz (1975) y en Europa occidental, aunque también con resonancias para América Latina, según el propio autor, el muy difundido trabajo de Melucci (2010).

¿Dónde aparecen estas prácticas discursivas? Se puede comenzar por mostrarlas en los principales enunciados que, en las tres primeras décadas del siglo XX, deja ver la trayectoria lamista de organización de cabildos y defensa de resguardos en varias parcialidades del Cauca. Allí, Quintín Lame, fue duramente perseguido por las autoridades locales, acusado de fundar una república chiquita, (Cf, MC, 2010c, 2010d, 2010e), es decir, un modo de organización sociopolítica que cuestionara los valores establecidos por la sociedad dominante, fuertemente influenciada por la discriminación colonial hacia los indígenas. Por esta razón, se desplaza hacia la década de 1917 y con gran preponderancia, desde los años 1930, al sur del Tolima, donde buscará defender, por medio de cabildos defendidos legalmente, algunos resguardos que allí residían, principalmente, los pertenecientes al otrora Gran Resguardo de Ortega y Chaparral, de los cuáles se pueden destacar algunas de las 26 comunidades tales como: San Antonio, Guatavita-Túa, Bocas del Tetuán, Vuelta’el Río, Aico, Guaipá, Yaguará, Santa Marta-Palmar, Chenche-AguaFría, Lomas de Hilarco, Chenche-Buenos Aires, Tinajas, Tamirco. Esta localización de los discursos, permite describir y analizar algunos postulados principales que, a modo de prácticas, hicieron posible el surgimiento o afianzamiento de un discurso sobre lo propiamente indígena en Quintín Lame y sus simpatizantes, y, a partir de ellos, mostrar qué formas de resistencia van apareciendo a su alrededor a través de sus respectivas formas de acción y organización.

Se puede destacar, en primera instancia, la descripción de una "razón práctica” (MC, 2010b, p. 36). Basada en una perspectiva moral de la justicia indígena histórica, ella se manifiesta como fuente de "las verdades del orden moral" (p. 36). Se trata de una verdad transversal a las leyes de los hombres en sociedad y en cuanto tal, permite concebir la acción de los sujetos en cuestión, la lucha por la justicia 
comunitaria y el desenmascaramiento de cualquier injusticia incluso -o con mayor razón- si se encuentra bajo el velo «sagrado» de la ley. De las prácticas sociales que recrean la acción del movimiento, va surgiendo la reflexión de éste en una reformulación recíproca donde el sujeto va definiendo su acción a través de principios. Es factible encontrar en su decir, a través de la reactivación de las luchas históricas, una razón que rompe las cadenas de la tiranía y la dominación (MC, 2010a, p. 58) que pretenden erigir "razones falsas" (p. 36) que han doblegado a anteriores generaciones que pretendían luchar para rescatar sus valores morales, su vigorosidad como raza, sus tradiciones y sus creencias cosmogónicas a través de la defensa de su territorio. De este modo, se recurre a la historia como lucha constante:

Y la lucha (...) de nosotros, desde cuándo... Y nuestros antepasados... nosotros yo les relato únicamente lo que yo vi, por ejemplo el 35, lo que me tocó, y lo que vi por ejemplo, donde mis abuelos. La cuestión del irrespeto, cosas pues, muy despreciadas. Recuerdo eso... pero de lo más allá, de lo más allá, eso es una lucha continua." (Entrevista a Escolástico Ducuara, 1987, Lado A).

Ejemplo de este ejercicio colectivo de racionalidad son las resonancias que los pobladores actuales poseen de la historia conflictiva que relata las fuerzas de los pueblos pijaos que resistieron a la dominación española por más de 70 años, esto es, desde 1550 hasta 1620 (Simón, 1892b, pp. 226228). Hacia 1605, se desata la guerra general de la Corona contra "72 pueblos y pobladores ancestrales" que existían en esa zona a cargo de Juan de Borja, Presidente de la Real Audiencia de Nueva Granada, de los cuales sólo 2 negociarán y se aliarán con la Corona para derrotar a los demás pueblos guerreros: los Coyaimas y Natagaimas; los demás serán “física y culturalmente exterminados.” (Entrevista 1, 07:0608:29). Negociar preserva la vida, contrarresta la muerte para permitirse luchar sociopolíticamente y poder gestionar sus territorios desde sus resguardos:

El título de tierras de resguardo se otorgaba a un cabildo compuesto por el cacique y sus principales. Los derechos de tierra se administraban por parte del cacique y el cabildo, quienes disfrutaban de ciertos privilegios como el derecho a poseer tierras privadas, a consumir artículos que estaban limitados a la población de origen europeo, a vestir ropas hechas en Europea (sic) y a recibir el tratamiento noble de «don»y «doña». El sistema original de resguardo se desarrolló como una forma más palpable y eficiente de penetración y explotación de las comunidades indígenas por parte de la Corona en un momento en el que sólo el diez por ciento de la población indígena había sobrevivido la devastación de la Conquista. (Rappaport, 2000, p. 77)

Al parecer, es este el momento en que emerge el resguardo como "estrategia de vida" (Vasco, 2002, p. 141) frente al derecho soberano de muerte del rey, lo cual es ya una clara acción de "gestión gubernamental" (Foucault, 2006, p. 135). Para el caso del Gran Resguardo de Ortega y Chaparral, su genealogía política de conservación de resguardos, podría empezar a rastrearse aquí - Al menos así lo manifiesta la entrevista a Ducuara (1987a, Lado A); la protocolización de los títulos ancestrales de 1917 en la Notaría 4a de Bogotá (CD/RAM, 1917) y en la actualidad (Entrevista 1, 04:40-04:49) - ya que se ve en este acontecimiento, las tácticas y la apropiación del derecho como "instrumento y efecto de poder, pero también [como] obstáculo, tope, punto de resistencia y de partida para una estrategia opuesta [al poder]." (Foucault, 1998, p. 123). Por poner un ejemplo, de los tres casos protocolizados en 1917 en la Notaría 4 a de Bogotá -1621, 1654, 1776- (CD/RAM, 1917) a raíz de conflictos 
presentarán su queja con el Fiscal en 1621, protector legal del indígena -"Ley xxj. Que los Fiscales defiendan los pleytos de Comunidades (sic). Expedida por Don Felipe III en Madrid á 10 de Febrero de 1619. (sic)" (Carlos II, 1774, pp. 204-205)- , quien intercederá por la entrega de sus cédulas reales, esto es, el "traspaso de los poderes de tierra" (CD/RAM, 1917, p. 24). Allí, en las tres entregas enunciadas, se describirá cuáles han de ser los linderos del territorio de la Gran Comunidad que serán utilizados como instrumentos legales de resistencia contra el despojo que buscan lograr los terratenientes. Será una de las continuidades del movimiento lamista en 1930 y, a partir de ahí, uno de sus instrumentos más importantes junto a los memoriales, de los cuales cuenta un miembro del resguardo Guatavita-Túa, en Ortega-Tolima (quien conoció personalmente a Lame), -"Ley xxj. Que los Fiscales defiendan los pleytos de Comunidades (sic). Expedida por Don Felipe III en Madrid á 10 de Febrero de 1619. (sic)" (Carlos II, 1774, pp. 204-205) - eran formas de escritura que les permitían defender legalmente a sus semejantes al dirigirse a los poderes locales, regionales y centrales para liberar a los indígenas que aquellos metían a las cárceles, por denunciar a quienes querían quitarles sus tierras, por desconocer la figura de los cabildos indígenas como legítimas y legales (reconocidas por ley 89 de 1890); en fin: por "reclamar sus derechos de origen que les han dejado sus ancestros, antepasados" (Entrevista 2, 06:23-06:32).

Se destaca, entonces, la territorialidad de los conflictos a través de un ejercicio de razón práctica, como "combate intelectual" (CD/RAM, 1939b), esto es, a partir de "la verdad, la razón, la ley y la justicia," (CD/RAM, 1934a) componente arqueológico y genealógico de gran parte del discurso de los indígenas lamistas en su defensa por el Gran Resguardo de Ortega y Chaparral y en general, como forma de reactivar las luchas olvidadas en el orden nacional, ya que, en principio, se referirá a "todos los pequeños cabildos de la Nueva Granada” (MC, 2010, p. 36). La apuesta histórica será transversal a sus discursividades y buscará "reivindicar sus derechos" frente a la tiranía española y de los ricos en su presente - La tendencia divisionista de resguardos desde el siglo XIX puede verse en Triana (1993); en su ontología, tal y "como reivindicó Dios la humanidad, es decir, la rescató de la tiranía del demonio" (Lame, 1939/1971, p. 133). El objetivo de utilizar la misma terminología con la que la civilización occidental, en este caso, española, buscó dominar a la raza indígena y sincretizar progresivamente sus prácticas, será el de mostrar una realidad teórica, filosófica, histórica y política de un discurso emergente de lucha por los derechos indígenas que busque abrir el espectro de la concepción humana, una búsqueda del sujeto ético en perspectiva universal. (Theodosiadis, 2004; Deleuze, 2005)

Dentro de esta ontología que constituye su concepción humanista del indígena, Quintín Lame enuncia, a nivel del individuo, la conciencia. En términos generales, se definirá como "el entendimiento en cuanto determina lo que el individuo debe hacer en los casos particulares" (MC, 2010b, p. 36). El hilo conductor de una y otra en su codificación, (razón y conciencia/sujeto e individuo), será el de constituirse en una verdad moral, que busca enlazar tanto las situaciones generales como las particulares a tal punto de obrar correctamente tanto en la vida pública como en la vida privada. En el cumplimiento del deber, como constituyente del sujeto ético al cual le apuesta Lame, a través de principios católicos como la honestidad y la rectitud moral, es posible encontrar, a modo de principio general de acción, un procedimiento para cabildantes indígenas como para servidores públicos estatales: 
(...) los cargos públicos deben ser ocupados por personas de actitud resueltamente reconocida, de otra suerte no se consiguiera (sic) el fin que con ello se persigue, deben ser individuos de reconocida probidad porque es la mejor garantía del cumplimiento del deber, los empleados deben ser convenientemente retribuidos porque así lo exige la justicia y la seguridad del bien público. (2010b, p. 44)

El deber, como fundamento ético del sujeto indígena así constituido, implica a su vez una concepción sobre lo público. Al parecer, se encuentra en lo enunciado sobre la organización del poder político un fundamento básico de su interpretación sobre teoría política liberal:

Es la función del poder supremo al cual corresponde la ejecución de las leyes, de lo que se deduce: I) Que en cualquier forma de gobierno el poder ejecutivo está subordinado al Legislativo; 2) que el poder constituyente debe fijar los límites de este poder judicial, que también es función propia del poder soberano, pero distinta del ejecutivo. (2010b, p. 37)

El juego discursivo que planteara Lame será el de abrir el espectro de representación de los poderes superiores tal como es el poder soberano que, a través de formas de resistencia como el Resguardo, el Cabildo y el Sindicato, pretenden expandir la noción de poder constituyente ya no desde el choque de poderes ejecutivo, legislativo y judicial sino, antes bien, desde la sociedad civil, permitiendo, a raíz de ésta, concebir su surgimiento como movimiento social de resistencia, ya que "él defiende, dentro de un campo cultural e histórico dado, otra sociedad" (Touraine, 2006, p. 258). Este otro plano de realidad no será otro que abrir un "horizonte para nosotros los indígenas ignorantes en el transcurso de 343 años, en que (...) hemos sido perseguidos, ultimados, despreciados, ultrajados, robados, sin ley, sin justicia, sin caridad, desde ese horrible día fechado el 12 de octubre de 1492. (CD/RAM, 1935; Lame, 1939/1971, p. 133). Múltiples fuerzas que continúan expropiando al indígena desde los tiempos de la Conquista Española y que no han cesado hasta el presente debido a la ambición de los terratenientes junto a las autoridades locales. Su principal forma de reivindicación fue la defensa de la justicia propia, entendida como un choque jurídico de fuerzas que permitió valer su reconocimiento de identidad como indígenas.

Dicho horizonte fue abierto en múltiples ocasiones por el Cabildo y por el Sindicato que, en cuanto formas de acción y organización variables, buscan defender la autoridad (CD/RAM, 1939a) de los resguardos indígenas que pertenecen legal y ancestralmente a sus dueños y en cuya lucha sus protestantes pretendían reivindicar su derecho político-económico en torno a la libertad de asociación y organización en analogía con partidos políticos, episcopados y el Vaticano (CD/RAM, 1935).

Por su parte, en 1934, el "Sindicato Indígena Nacional", con la asistencia de 3861 indígenas en San José de Indias, fracción de Loaní y Toy, Ortega, Tolima, se reunió para elegir "cuatro miembros": Presidente, Vicepresidente, Tercer Miembro, Cuarto Miembro y Secretario General. Esta táctica se realizó "porque de otro modo no se podía hacer respetar los resguardos." (CD/RAM, 1934a). Desde 1930, se venía conformando el Cabildo pero "el mismo alcalde lo declaró nulo y de valor ninguno, es decir, el Alcalde de Ortega, reunido con el Fiscal del Tribunal Superior de Ibagué” (CD/RAM, 1934b). Resonancias posteriores serían reactivadas por organizaciones como el CRIT, el CRIC y la ONIC, a partir de 1980, que evidencian la necesidad de potenciar una forma de autogobierno diferente a la otorgada por los cabildos, en escala regional y nacional, frente a los que luego se les criticó como "gobiernos títeres" (Vasco, 2008, p. 376), sujetos a las redes de poder antes descritas. 
Pese a su crítica, es viable afirmar que no se abandonó este mecanismo político de defensa, tendiente a la gestión de su población. La acción a través de Cabildos desde la legalidad se basó en una perspectiva de valores éticos y morales de comunidad. La lucha continúa; como práctica discursiva visibiliza la apuesta ética-moral del movimiento indígena, circulando a través de la reverberación de las luchas de los ancestros pijaos, coyaimas y natagaimas, del uso estratégico político de la ley 89 de 1890 así como también del reconocimiento de su identidad a través de las cédulas reales otorgadas desde 1621. En realidad, éstos son instrumentos que verifican sus derechos soberanos como "resguardo indígena" y no solo como "comunidad civil" (CD/RAM, 1938); ellos viabilizan una plataforma de lucha sociopolítica para futuras reelaboraciones reivindicatorias y de restitución de tierras en el presente (Entrevista 3, 04:12-04:41; Entrevista 1, 04:40-04:49), pues son clara evidencia de una formación discursiva aún no certificada pero no por ello olvidada.

\section{A modo de cierre}

Del registro de las prácticas discursivas inherentes al movimiento lamista en el Sur del Tolima, donde se busca defender el territorio de la Gran Comunidad de Ortega y Chaparral como la llaman sus pobladores actuales-, se buscó movilizar un saber filosófico-político en torno a la verdad moral que une la razón y la conciencia, (ora de los sujetos, ora de los individuos), en torno a una misma colectividad indígena nacional, localizada en los resguardos de Ortega, Chaparral, Natagaima y Coyaima, pero orientada también, -con fuerza y reverberación-, hacia los resguardos del Huila y el Cauca.

Su formación discursiva, como emergencia de plataforma política de lucha colectiva para otras organizaciones, se puede resumir en los siguientes puntos: 1. La desobediencia a pagar terraje en predios de resguardos; 2. La autonomía local a través de la figura ancestral de éstos; 3. El ejercicio del poder soberano mediante la gestión gubernamental comunitaria de resguardos a través de cabildos indígenas; 4. La difusión de tácticas de utilización de la ley como formas de resistencia autóctona; 5. El reconocimiento de la historia colonial de sus ancestros puesta en práctica en el presente para desarrollar estrategias modernas de gestión territorial que vislumbren el porvenir de su consolidación como comunidades; 6. El reconocimiento de identidades indígenas en perspectiva política, es decir, recuperación, ampliación y defensa del territorio de resguardos y, por último, 7. Una concepción política de la justicia en clave histórica, gubernamental, jurídica y cultural. (Lame, 1939/1971).

Frente a la práctica discursiva sobre la identidad, problema manifestado en la aparente fragmentación del movimiento social como en la demostración efectiva de la pertenencia a un resguardo indígena, la búsqueda del ejercicio de un poder soberano estará localizada en mecanismos de representación como el Cabildo y el Sindicato que disputan el territorio contra, a través de, y hacia la legalidad. Aquí convergen en un mismo punto un saber filosófico-político que se encuentra orientado por principios morales y un saber económico-político sobre la administración del territorio. Allí radica el conflicto por la autonomía.

Como práctica discursiva transversal, el saber histórico-político permite construir en múltiples formas la lucha por la identidad diferente y la autonomía territorial; la interpretación político-jurídica de las leyes; la constitución de un sujeto activo en la participación comunitaria; la posibilidad de disentir frente al reconocimiento de leyes injustas que se funden en un proyecto dominador ancestral. De este modo, el derecho a la resistencia, como forma legítima de lucha indígena, puede ser formulado. 
Siguiendo una lógica en el desarrollo del conocimiento, en el entender de Foucault, se puede ver aquí cómo se transita de una práctica discursiva a una formación discursiva, pues este umbral se ha cruzado en la medida en que la práctica desarrollada por Lame ha propiciado la elaboración de un discurso sociopolítico que da consistencia a las luchas por los derechos indígenas en Colombia; se ha posicionado y legitimado, al punto que, se podría decir, está en la instancia de hacer emerger un régimen epistemológico mediante el cual se ha de producir un discurso indígena, no sólo legal y legítimo sino disciplinado, organizado, sistematizado, en el cual se puede ver la posibilidad de superación de representación local para tener la pretensión de alcance regional, nacional y continental, lo cual ha de hacer de este un discurso general que habla en favor de una forma de civilización diferente pero no contraria a los ideales mismos de las sociedades políticas en los que se afincan las culturas de Occidente.

Con este telón de fondo, una premisa metodológica descubierta no fue tanto la resistencia al conflicto, sino antes bien, la resistencia entre conflictos, es decir, la serie de mecanismos y dispositivos de poder utilizados de un lado y de otro en un enfrentamiento transversal y (dis)continuo por la recuperación territorial de la raza indígena, frente a la usurpación de sus adversarios españoles, blancos y mestizos, para reivindicar sus derechos como legítimos pobladores y resistirse a desaparecer a través de la ley, la historia, la ética y la moral, (Triana, 1993, p. 100), factores constituyentes de sujeto en su perspectiva propia de resistencia, que permiten considerarlo, a su vez, como un movimiento sociopolítico, ya que para quienes reconocen su importancia, Lame fue "un caudillo de (...) trabajo organizativo"; "un pionero" (Entrevista 4, 29:52-29:56; Cf. Entrevista 2, 05:00-07:31).

\section{Referencias bibliográficas.}

Ariza, L. J. (2009). Derecho, saber e identidad indígena. Bogotá: Siglo del Hombre Editores, Universidad de los Andes, Pontificia Universidad Javeriana.

Castrillón Arboleda, D. (1973). El indio Quintín Lame. Bogotá: Tercer Mundo.

Deleuze, G. (2005). Repetición y diferencia. Barcelona: Anagrama, pp. 49-105.

Foucault, M. (1970). La arqueología del saber. Bogotá.: Siglo XXI.

Foucault, M. (1996). Genealogía del racismo. La Plata: Altamira.

Foucault, M. (1998). Historia de la sexualidad I: la voluntad de saber. México D.F.: Siglo XXI.

Foucault, M. (2006). Seguridad, territorio, población. Curso en el Collège de France (1977-1978). Buenos Aires: Fondo de Cultura Económica.

Foucault, M. (2010). El orden del discurso. Barcelona: Tusquets.

Gros, C. (2012). Políticas de la etnicidad: identidad, Estado y modernidad. Bogotá: Instituto Colombiano de Antropología e Historia.

Guerra Rodríguez, C. (1997). "Hacia una sociología del sujeto: democracia y sociedad civil.” En: Hugo Zemelman Guzmán \& Emma León Vega (coords.) Subjetividad: umbrales del pensamiento social. Barcelona: Anthropos.

Lomnitz, L. A. (1975). Cómo sobreviven los marginados. México D.F.: Siglo XXI.

Melucci, A. (2010). Acción colectiva, vida cotidiana y democracia. México.: El Colegio de México, Centro de Estudios Sociológicos. 
Rappaport, J. (2000). La política de la memoria: Interpretación indígena de la historia en los andes colombianos. Popayán: Editorial Universidad del Cauca. Traducción: José Ramón Jouvé Martín.

Raschke, J. (1994). "Sobre el concepto de movimiento social”. En: Zona Abierta, 69, 121-134.

Rojas, J. M. (2000). “Ocupación y recuperación de los territorios indígenas en Colombia”. En: Análisis político, 41, pp. 71-86.

Tarrow, S. (1997). El poder en movimiento. Los movimientos sociales, la acción colectiva y la politica. Madrid: Alianza.

Tello, Piedad. (1986). “Aspectos históricos del resguardo indígena y su defensa a fines del siglo XIX e inicios del XX”. En: Revista de Antropología. 2 (1), pp. 136-152 (Versión digital). Consultado el 7 de septiembre de 2016 en: http://antipoda.uniandes.edu.co/datos/pdf/descargar.php?f=./data/Rev antigua/v02n12.pdf\#page $=136$

Theodosiadis, Francisco. (2004). “Quintín Lame: ¿Brújula del pensamiento de resistencia autóctona?”. En: Jaramillo, María Mercedes, Betty Osorio y Ángela Inés Robledo (Comps.). Literatura y cultura. Narrativa colombiana del siglo XX. Vol. 3: Hibridezy Alteridades. Bogotá, D.C.: Biblioteca Virtual del Banco de la República.

Touraine, A. (1997) ¿Podremos vivir juntos? Iguales y diferentes. Brasil: Fondo de Cultura Económica.

Triana, A. (1993). "Los resguardos indígenas del Sur del Tolima." En: Encrucijadas de Colombia Amerindia. François Correa (ed.). Bogotá: Instituto Colombiano de Antropología.

Vasco Uribe, L. G. (2002). Entre selva y páramo, viviendo y pensando la lucha india. Bogotá: Instituto Colombiano de Antropología e Historia.

Vasco Uribe, L. G. (2008). “Quintín Lame: Resistencia y liberación”. En: Tabula Rasa. (9), pp. 371383.

\section{Fuentes primarias.}

\section{Actas, certificados y constancias de la existencia del Sindicato y del Cabildo indígenas.}

CD/RAM. (Centro de Documentación Regional del Alto Magdalena). (1934a) [01/10/1934]. “Acta No. 1 de constitución del Sindicato Indígena Nacional”. Caja No. 2. No. Legajos: 18. Serie: Documentación Indígena del Sur del Tolima. Subserie: Documentos de Quintín Lame. No. Legajo: 34; No. Folios: 36. En: Archivo General de la Nación. Universidad del Tolima, Facultad de Educación: Museo Antropológico: CD/RAM.

CD/RAM. (Centro de Documentación Regional del Alto Magdalena). (1934b) [08/10/1934]. "Pliego de peticiones de las grandes comunidades de indígenas de Ortega y Chaparral-Departamento del Tolima. Quienes están representados hoy por un "Sindicato Indígena Nacional." Caja No. 2. No. Legajos: 18. Serie: Documentación Indígena del Sur del Tolima. Subserie: Documentos de Quintín Lame. No. Legajo: 34; No. Folios: 36. En: Archivo General de la Nación. Universidad del Tolima, Facultad de Educación: Museo Antropológico: CD/RAM.

CD/RAM. (Centro de Documentación Regional del Alto Magdalena). (1939a) [04/09/1939]. "Solicitud de defensa al Ministro de Economía para que se reconozca la autoridad del Cabildo indígena dentro del Gran Resguardo de Ortega y Chaparral-Fracción del Alto Ortega en Ortega-Tolima” Caja No. 2. No. Legajos: 18. Serie: Documentación Indígena del Sur del 
Tolima. Subserie: Documentos de Quintín Lame. No. Legajo: 34; No. Folios: 36. En: Archivo General de la Nación. Universidad del Tolima, Facultad de Educación: Museo Antropológico: CD/RAM.

CD/RAM. (Centro de Documentación Regional del Alto Magdalena). (1939b) [29/09/1939]. "Derecho de petición sobre por qué hasta el momento el Ministro de Economía desconoce el Cabildo de Indígenas del Gran Resguardo de Ortega y Chaparral” Caja No. 2. No. Legajos: 18. Serie: Documentación Indígena del Sur del Tolima. Subserie: Documentos de Quintín Lame. No. Legajo: 34; No. Folios: 36. En: Archivo General de la Nación. Universidad del Tolima, Facultad de Educación: Museo Antropológico: CD/RAM.

CD/RAM. (Centro de Documentación Regional del Alto Magdalena). (1939c) [29/09/1939]. "Sobre la inspección ocular favorable que tuvieron los resguardos por parte de un representante de la Procuraduría General de la Nación.” Caja No. 2. No. Legajos: 18. Serie: Documentación Indígena del Sur del Tolima. Subserie: Documentos de Quintín Lame. No. Legajo: 34; No. Folios: 36. En: Archivo General de la Nación. Universidad del Tolima, Facultad de Educación: Museo Antropológico: $C D / \mathrm{R} A M$.

\section{Memoriales dirigidos por Quintín Lame y sus colegas a las autoridades del país.}

CD/RAM. (Centro de Documentación Regional del Alto Magdalena). (1935) [17/01/1935]. "Memorial dirigido por Manuel Quintín Lame al Ministro de Industrias". Caja No. 2. No. Legajos: 18. Serie: Documentación Indígena del Sur del Tolima. Subserie: Documentos de Quintín Lame. No. Legajo: 34; No. Folios: 36. En: Archivo General de la Nación. Universidad del Tolima, Facultad de Educación: Museo Antropológico - CD/RAM (Centro de Documentación Regional del Alto Magdalena).

CD/RAM. (Centro de Documentación Regional del Alto Magdalena). (1938). [04/01/1938]. "Memorial dirigido por Manuel Quintín Lame al Ministro de Agricultura". Caja No. 2. No. Legajos: 18. Serie: Documentación Indígena del Sur del Tolima. Subserie: Documentos de Quintín Lame. No. Legajo: 34; No. Folios: 36. En: Archivo General de la Nación. Universidad del Tolima, Facultad de Educación: Museo Antropológico - CD/RAM (Centro de Documentación Regional del Alto Magdalena).

\section{Crónicas, textos antiguos y raros.}

Carlos II-. (1774). Recopilación de leyes de los Reynos de las Indias. Madrid: Andrés Ortega, imprenta del rey. Tomo II.

De las Casas, B. (1552). Brevíssima relación de la destruyción delas Indias: colegida por el Obispo don fray Bartolomé de las Casas/o Casaus dela orden de Santo Domingo. Sevilla: Imprenta de Sebastián Trugillo.

Lame Chantré, Manuel Quintín. (1939/1971). En defensa de mi raza. Bogotá: Comité de defensa del indio.

Lame Chantré, Manuel Quintín. (1939/1987). Los pensamientos del indio que se educó dentro de las selvas colombianas. Bogotá: Organización Nacional Indígena de Colombia.

Ministerio de Cultura. (2010a). "Carta dirigida a sus hermanos Gregorio Nacianceno Lame e Ignacio Lame, 11 de enero de 1915: Manuel Quintín Lame”. En: Sánchez Gutiérrez, Enrique \& 
Hernán Molina Echeverri (comps.). (2010). Documentos para la historia del movimiento indígena contemporáneo. (pp. 58-61). Bogotá: Ministerio de Cultura.

Ministerio de Cultura. (2010b). "Luz indígena en Colombia: Manuel Quintín Lame”. En: Sánchez Gutiérrez, Enrique \& Hernán Molina Echeverri (comps.). Documentos para la historia del movimiento indígena contemporáneo. (pp. 36-45). Bogotá: Ministerio de Cultura.

Ministerio de Cultura. (2010c). "Circular del primero de mayo de 1916: Manuel Quintín Lame”. En: Sánchez Gutiérrez, Enrique \& Hernán Molina Echeverri (comps.). (2010). Documentos para la bistoria del movimiento indígena contemporáneo. (pp. 46-50). Bogotá: Ministerio de Cultura.

Ministerio de Cultura. (2010d). "Nota periodística del 2 de junio de 1916: Manuel Quintín Lame". En: Sánchez Gutiérrez, Enrique \& Hernán Molina Echeverri (comps.). (2010). Documentos para la bistoria del movimiento indígena contemporáneo. (pp. 51-53). Bogotá: Ministerio de Cultura.

Ministerio de Cultura. (2010e). "Nota periodística del 9 de junio de 1916, El Cauca Liberal: Manuel Quintín Lame”. En: Sánchez Gutiérrez, Enrique \& Hernán Molina Echeverri (comps.). (2010). Documentos para la bistoria del movimiento indígena contemporáneo. (pp. 54-57). Bogotá: Ministerio de Cultura.

Simón, Fray Pedro. (1627/1892). Noticias historiales de las conquistas de Tierra Firme en las Indias Occidentales. Tercera parte, Tomo V. Bogotá: Casa Editorial de Medardo Rivas.

\section{Fuentes orales.}

Entrevista 1 (confidencial). (2016, 8 de julio de). Miembro perteneciente al resguardo Vuelta el' Río (Ortega, Tolima). [Grabación personal en formato Mp3]. 20 min. Ibagué, Tolima: Colombia.

Entrevista 2 (confidencial). (2016, 27 de agosto de). Miembro perteneciente al resguardo GuatavitaTúa. [Grabación personal en formato Mp3]. $31 \mathrm{~min}$. Ortega, Tolima: Colombia.

Entrevista 3 (confidencial). (2016, 27 de agosto de). Miembro perteneciente al resguardo GuatavitaTúa. [Grabación personal en formato Mp3]. 27 min. Ortega, Tolima: Colombia.

Entrevista 4 (confidencial). (2016, 27 de agosto de). Miembro perteneciente al resguardo GuatavitaTúa. [Grabación personal en formato Mp3]. 45 min. Ortega, Tolima: Colombia.

Velandia, C. \& Buitrago, J. del C. (Entrevistadores), Ducuara, Escolástico (Entrevistado). (1987, 26 de septiembre de). Problema Indígena. [Entrevista transcrita]. Casete $\mathrm{N}^{\circ} 1$ (60 min). Yaguara; Chaparral, Tolima: Colombia. En: CD/RAM (Centro de Documentación Regional del Alto Magdalena). Serie: Documentación auditiva. Numeración: Cassettes 34. Museo Antropológico. Universidad del Tolima.

\section{Notas:}

${ }^{i}$ Desarrollos producidos en torno del proyecto investigativo: "Movimientos sociales de resistencia y su constitución como movimiento político: el caso del movimiento Quintín Lame en el sur del Tolima, entre 1931-1939", financiado por la Universidad del Tolima con recursos de regalías, bajo el código: 140220516. Este proyecto comenzó en abril-2016 y finalizó en marzo-2017. 